
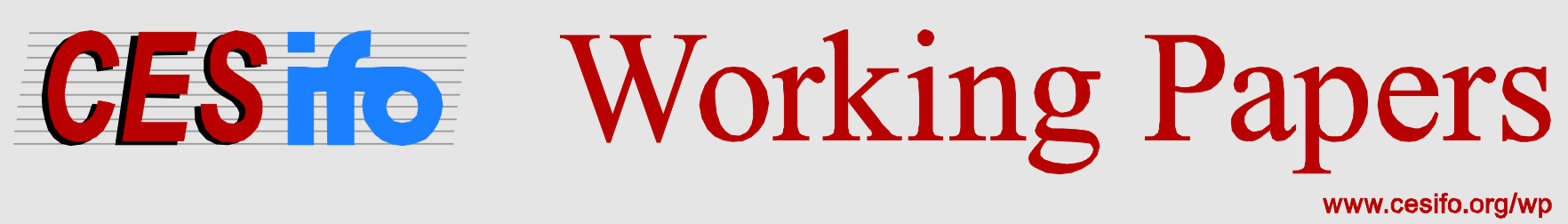

\title{
Compliance Costs, Corruption and the Differentiation of Bureaucratic Services
}

\author{
André Seidel \\ CESIFO WORKING PAPER NO. 5683 \\ CATEgory 2: Public CHOICE \\ DECEMBER 2015 \\ An electronic version of the paper may be downloaded \\ - from the SSRN website: Www.SSRN.com \\ - from the RePEc website: Www.RePEc.org \\ - from the CESifo website: www.CESifo-group.org/wp
}




\title{
Compliance Costs, Corruption and the Differentiation of Bureaucratic Services
}

\begin{abstract}
How to fight petty day-to-day corruption is a question often debated by politicians, by the public and in the economic literature. Early studies have noted that a simple and well-known way to fight day-to-day corruption is to create competition among corrupt officials. This paper shows that even a benevolent government might not encourage competition among officials in a way that eliminates corruption. This is due to a tradeoff between corruption and compliance costs. More differentiated bureaucratic services decrease compliance costs but increase the leeway for extortion. The analysis further reveals that exogenous shocks, for example in the form of foreign aid that aims to improve anti-corruption capacities, may prompt a benevolent government to increase the differentiation of bureaucratic services, thereby leading to an increase in corruption.
\end{abstract}

JEL-Codes: D730, L130.

Keywords: corruption, compliance costs, bureaucratic competition.

\author{
André Seidel \\ TU Dresden \\ Dresden / Germany \\ andre.seidel1@tu-dresden.de
}

This Version: 12.17.2015

Financial support from the Deutsche Forschungsgemeinschaft (Grant 759-3) is gratefully acknowledged. 


\section{INTRODUCTION}

Fighting extortive petty day-to-day corruption is an important task. The individual payments may be small, but they may nevertheless slow growth substantially when combined. Unfortunately, fighting petty corruption is also a difficult task, as the costs of monitoring and punishing are often higher than the gains resulting from reduced extortion. Early studies have noted that a simple and perhaps cheap way of fighting petty corruption involves encouraging competition among corrupt officials. With perfect competition among bureaucrats, extortion should cease to exist because each official offering the same bureaucratic service has an interest in decreasing his demanded bribe to attract more customers. Finding examples of cases around the world in which citizens can choose among various officials who offer the same bureaucratic service is not difficult. For example, entrepreneurs in South Africa need to visit an office of the South African Revenue Service (SARS) to register their business before opening it (World Bank, 2016). Using this bureaucratic service is mandatory and is supposed to be free of charge. Furthermore, entrepreneurs can choose the office that they visit for registration. ${ }^{1}$ In Johannesburg alone, entrepreneurs can choose from seven offices.

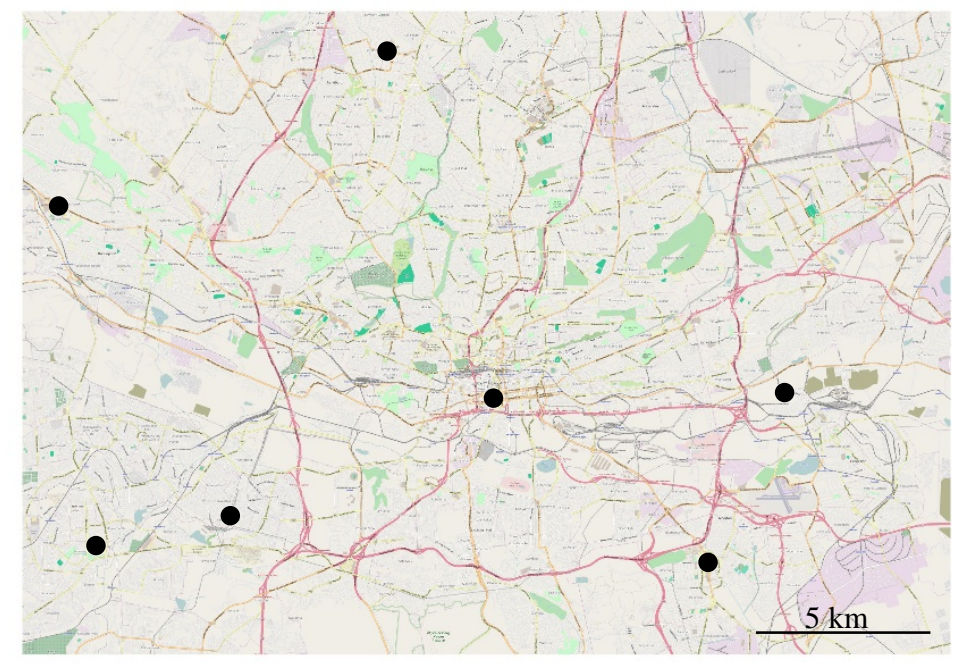

Figure 1: Location of SARS offices in Johannesburg, South Africa (C OpenStreetMap contributors.

The previous economic literature suggests that the potential for extortion during the registration of a business in Johannesburg should be zero. ${ }^{2}$ However, this not necessarily true because competition among officials is probably imperfect. ${ }^{3}$ Figure 1 illustrates that the offices (represented by dots) are located in different locations across Johannesburg, and we know from the literature on industrial organization that, in such cases, competition will be imperfect because of transportation costs. For entrepreneurs who are located somewhere in Johannesburg, bureaucratic services are imperfect substitutes because they face different transportation costs when traveling between different offices. Consequently, no race to the bottom will occur, and extortion may persist despite the competition among corrupt officials. Therefore, the question arises: Why does a government

\footnotetext{
1 They are even encouraged to search online for the SARS office with the shortest queue beforehand: http://www.sars.gov.za/Contact/Pages/Check\%20the\%20shortest\%20queue.aspx.

${ }^{2}$ A notable exception is Drugov (2010), which is discussed further along in this section.

${ }^{3}$ Reports from Transparency International on corruption in South Africa support this suspicion. From 2010 to 2011, bribes in South Africa were mostly paid for two core bureaucratic services: the police and registry and permit services (Transparency International, 2011).
} 
position officials who offer the same bureaucratic services in different places across town, when such an arrangement may increase the leeway for extortive corruption. A possible answer to this question is that governments may face a tradeoff between compliance costs and bribery. When asked about business constraints, entrepreneurs and politicians around the globe consistently report the costs of complying with government regulations. Therefore as a mean to foster growth, decreasing compliance costs is a frequent goal of governments. One possible way to achieve this is to give citizens the possibility to comply with a regulation at a government office that is closely located to their home or business. For example, in South Africa, compliance costs may be low, as entrepreneurs can register their businesses in their neighborhood tax offices instead of traveling to a single large tax office in the city center. ${ }^{4}$ Several other possibilities can decrease the costs of complying with government regulations. All of these methods are only possible if different officials offer the same basic services but at different times, at different places, or in different languages. Hence, decreasing compliance cots often involves the government's differentiation of bureaucratic services. Increased bribery, resulting from the differentiation of bureaucratic services, is thus perhaps accompanied by a substantial decrease in compliance costs. This paper discusses this tradeoff in detail and subsequently attempts to determine the circumstances under which a government will differentiate bureaucratic services, despite the risk of increased bribery. $^{5}$

To answer this question, I develop a model of imperfect horizontal competition among corrupt officials, which is, to the best of my knowledge, new to the literature. The previous literature on corruption shows that extortion can be analyzed using models of industrial organization, which have been developed to analyze normal product markets (Choi and Thum, 2003, 2004, 2005; Seidel and Thum, 2016; Olken and Barron, 2009; Shleifer and Vishny, 1993). Early contributions to the literature primarily concentrate on the theory of vertical competition among corrupt officials; see, for example, Shleifer and Vishny (1993). This theory has received increasing attention in the recent years in empirical studies. Studies show that vertical competition drives the size and quantity of bribes (see, for example, Diabya and Sylwester, 2014; Olken and Barron, 2009; Khan et al., 2015; Svensson, 2003). Although horizontal competition among bureaucrats was, from early contributions to the literature (see, for example, Rose-Ackerman, 1978), part of the discussion on market forces and bribery, it has received much less attention in recent years. Only a few theoretical papers discuss the effect of horizontal competition among officials on extortion. These analyses usually assume that citizens have no information about the bribes demanded by different officials; therefore, they have to search for the best offer among the available officials. Hence, bureaucratic competition is imperfect due to the search costs involved (Drugov, 2010; Ryvkin and Serra, 2013). However, recent empirical studies indicate that citizens often have at least some information on the bribes demanded by each official. For example, a field experiment on the extortion of truckers in Indonesia observed that, "in most cases, the driver simply handed over the payment without discussion and continued on his way.” (Olken and Barron, 2009). Hence, there is reason to believe that, especially for petty

\footnotetext{
${ }^{4}$ The Doing Business reports of 2015 suggest that decreasing compliance costs seems to be one of the main reasons behind the differentiation of the SARS braches in South Africa.

${ }^{5}$ In some ways, this tradeoff is similar to the tradeoff described by Oates (1972), when he asked whether a country should become federalized. Ample literature builds on this question, theoretically and empirically debating the advantages and disadvantages of decentralization in terms of the percent of corruption at the macro level; see, for example, Arikan, (2004), Fisman and Gatti (2002a, 2002b) or Lessmann and Markwardt (2010). This literature focuses on the effect of grand corruption and the related economy policy issues such as taxation and budgeting, whereas in this I focus on petty corruption, enforcement and compliance issues in the tradition of Shleifer and Vishny (1993).
} 
corruption, citizens know what bribe to pay. In this paper, I argue that bureaucratic competition can nevertheless be imperfect when the services offered by corrupt officials are dissimilar. To the best of my knowledge, in the economic literature, no detailed analysis has examined the effect of the differentiation of bureaucratic services on corrupt officials' extortive behavior and activities.

The model developed in this paper builds on assumptions similar to those common to the analysis of differentiation in normal product markets (d'Aspremont et al., 1979; Hotelling, 1929). However, the analysis differs greatly in one respect, i.e., from the traditional analysis of product differentiation. In the case of imperfect competition among corrupt officials, the government, not the officials (i.e., the sellers of bureaucratic services), realizes the differentiation of the bureaucratic services. A government can decide to differentiate bureaucratic services to lower compliance costs; however, the analysis shows that such differentiation comes at the cost of increasing bribe payments. Therefore, a benevolent government will only differentiate bureaucratic services when the social costs of bribe payments are low. The analysis further shows that a benevolent government may still differentiate bureaucratic services when other factors beyond competition limit extortion (e.g., when the capacities to fight corruption are well developed, such that the cost of reporting extortion is low). Such action may necessitate the evaluation of development projects with a broad scope. Improved anticorruption capacities may prompt a government to start differentiating bureaucratic services because the resulting increase in bribery is suddenly sufficiently limited. As a result, the model shows that an increase in anti-corruption capacities may increase bribe payments. Nevertheless, total welfare increases because, in addition to the increase in bribery, compliance costs decrease substantially.

In the next section, I will develop the basic model. The basic model allows a detailed analysis of the principal tradeoff between compliance costs and corruption. In Section 3, I extend the basic model to account for anticorruption measures and their influence on the differentiation of bureaucratic services. Section 4 concludes.

\section{BUREAUCRATIC SERVICE DIFFERENTIATION AND CORRUPTION}

Defined very broadly, a government official's purpose is to deliver some kind of bureaucratic service, such as the issuance of birth certificates. In most cases, the same bureaucratic service is offered by several officials, and citizens can sometimes even choose the provider of said bureaucratic service. However, the services offered by different officials frequently appear to be the same. For example, take two officials who register businesses and whose offices are located in different areas of a particular city. The service that they deliver is the same at either location; however, the costs of traveling to the officials' offices may differ for citizens who live in different parts of the city. Therefore, from the perspective of an individual citizen, the services offered by the two officials are not perfect substitutes. The bureaucratic services that officials offer can differ in many other ways, for example, the delivery time or the language used. As in normal product markets, these characteristics will potentially influence prices or, in this case, the bribe that corrupt officials will charge for their services. However, in contrast to the situation in normal product markets, the officials do decide whether to differentiate themselves from their competitors. Government decisions determine most of the characteristics of bureaucratic services, for example, the location of tax offices and their opening hours. Quite naturally, a two-stage game follows. In the first stage of the game, the government decides on the characteristics of the bureaucratic services 
offered by each official. A government can differentiate bureaucratic services by implementing heterogeneous characteristics. In the second stage, the corrupt officials compete for bribes.

\section{Stage 2: Extortion with imperfect competition}

The analysis starts with the last stage of the game, the price competition between the two officials. Two profitmaximizing corrupt officials $i \in(A, B)$ offer the same bureaucratic services. However, the officials' service deliveries differ with respect to a one-dimensional characteristic. The amount of characteristics is measured by $z_{i}$, where $z_{i} \epsilon[0,1]$. In the main part of the paper, I only consider symmetric allocations of bureaucratic service characteristics, where $z_{A}<z_{B}$ and $z_{A}=1-z_{B}$. Hence, the service characteristics are always equally far from the fringes of the service characteristic space, and official $A$ always offers a service to the left of the service of official $B$ in the service characteristic space. This assumption substantially reduces the calculus of the analysis and has no significant influence on the main results of the paper. ${ }^{6}$ To simplify notation further, let us define the distance between the service characteristics of official $A$ and official $B$ as $\Delta$, where $\Delta \equiv z_{B}-z_{A}$. Figure 1 illustrates the allocation of the service characteristics offered by the two officials in the service characteristic space.

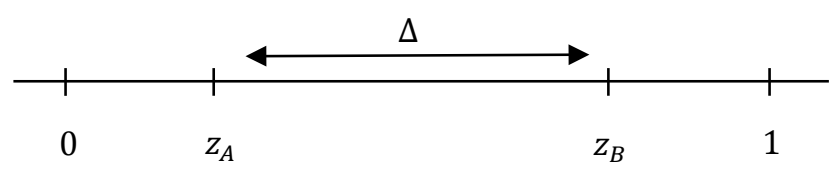

Figure 2: The service characteristics offered by the two officials.

Each official demands a uniform bribe $p_{i}$ from all the citizens who use his service. ${ }^{7}$ The officials offer their services at zero marginal cost. ${ }^{8}$ By law, using the service of at least one official is mandatory and is supposed to be free of charge for all citizens. ${ }^{9}$ Examples for these free mandatory bureaucratic services include business registrations or the issuance of birth certificates.

An infinite number of citizens exists, indexed by $j \in \mathbb{R}$. Each citizen prefers a specific individual bureaucratic service characteristic $z_{j}$. Preferences are uniformly distributed over the space of possible bureaucratic service characteristics $[0,1]$. When the characteristic of the bureaucratic service used deviates from the preferred service characteristic, a citizen suffers a disutility that has a monetary equivalent to $c \cdot\left[z_{i}-z_{j}\right]^{2}$. I will refer to these costs as compliance costs. Even with no corruption, citizens will have to endure these costs because the government regulation forces them to use this bureaucratic service. In the presence of corruption, citizens face the costs of extortion on top of the compliance costs. All citizens know the bribe demanded by each official and

\footnotetext{
${ }^{6}$ See Appendices A and D for a discussion on the model results when non-symmetric characteristics are possible.

${ }^{7}$ I assume that officials cannot distinguish between citizens. This assumption is obviously a major simplification. Empirical findings indicate that officials often have some information on their victims, which they use to optimize their bribe demands (see, for example, Olken and Barron (2009)). However, these studies further show that corrupt officials do not have all the information that they would like to have, for example, because of transaction costs. To compensate for missing information, corrupt officials use assumptions about the distribution of attributes of their victims and competitors to increase their profits. To keep the analysis focused, I only discuss this determinant of extortion.

${ }^{8}$ This assumption is somewhat relaxed in Section 3.

${ }^{9}$ As in Shleifer and Vishny (1993), I only consider cases of pure extortion. See, for example, Drugov (2010) for a discussion on the welfare effect of collusive corruption in the presence of negative externalities created by citizens who are not eligible for a bureaucratic service that is only received through bribery.
} 
the characteristics of the services that the officials offer. ${ }^{10} \mathrm{~A}$ citizen with $z_{j}=x$ is indifferent about using the service of official $A$ or official $B$, where $x$ is defined as follows:

$$
p_{A}+c \cdot\left[x-z_{A}\right]^{2}=p_{B}+c \cdot\left[z_{B}-x\right]^{2} .
$$

All citizens who live to the left of this citizen will prefer to acquire the services from official $A$, while all citizens who live to his right will prefer to acquire services from official $B$. Therefore, the corresponding demand that official $A$ faces is as follows:

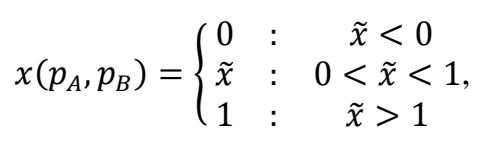

where $\tilde{x}=\left[c \cdot \Delta-p_{A}+p_{B}\right] /[2 \cdot c \cdot \Delta]$. The respective demand that official $B$ faces is $1-x$. The officials maximize their profit $\pi_{i}$ by choosing the bribe $p_{i}$. Both officials' gains from extortion are as follows:

$$
\begin{gathered}
\pi_{A}=p_{A} \cdot x, \\
\pi_{B}=p_{B} \cdot[1-x] .
\end{gathered}
$$

Competition constrains both officials in their attempts to maximize profits. According to [2], an increase in the bribe demanded by one official decreases the number of citizens who use this official's service and increases the number of citizens who use his opponent's service $\left(\frac{d x}{d p_{A}} \leq 0\right.$ and $\frac{d x}{d p_{B}} \geq 0$ ). Therefore, when increasing the bribe that he demands, an official has to weigh the losses due to fewer citizens using his service against the gains from the higher payments of the citizens still using his service. Both officials face this situation; therefore, the bribe that an official demands depends on the bribe demanded by his competitor, and vice versa. To find the equilibrium bribe, we have to derive the best responses of an official to all the bribes demanded by his opponent.

Let us start with the simplest scenario and assume for a moment that bribes are such that the marginal citizen is not located at one of the ends of the service characteristic space $(0<\tilde{x}<1)$. In this case, we can derive from [2] and [3] that official $A$ 's best response to the price $p_{B}$ demanded by official $\mathrm{B}$ is as follows:

$$
p_{A}=\frac{1}{2} \cdot \Delta \cdot c+\frac{1}{2} \cdot p_{B}
$$

Official $A$ will demand a higher bribe when the service characteristics are quite distinct $(\Delta)$ and the disutility of any deviation from the preferred service characteristic is high $(c)$. Therefore, we already see that the competition between the two officials limits the bribe that officials can demand. However, we also see that even if official $B$ demands no bribe, official $A$ will still demand a positive bribe. Official $A$ can make this demand because the difference in the service characteristics make the service offered by his opponent an imperfect substitute.

So far, we have assumed that bribes are such that the marginal citizen is not located at either end of the service characteristic space $(0<\tilde{x}<1)$. Using [2] and [5], we derive that, in a case where official $B$ demands $p_{B}=0$

\footnotetext{
${ }^{10}$ Recent empirical studies support this assumption. It seems that at least petty bribery often practically occurs without speaking because both sides know the price up front; see, for example, Olken and Barron (2009).
} 
and official $A$ demands $p_{A}=\frac{1}{2} \cdot c \cdot \Delta$, the marginal citizen will be located at $x=1 /[4 \cdot c \cdot \Delta]$. Hence, as long as official $A$ reacts as defined in [5], the marginal citizen will never be located at the left end of the service characteristic space, which is not necessarily true for the right side. If the bribe demanded by official $B$ is very high, the marginal citizen may be located at the right end of the service characteristic space. For example, suppose that official $A$ demands $p_{A}=\frac{1}{2} \cdot c \cdot \Delta+\frac{1}{2} \cdot p_{B}$. In this case, we can then derive from [2] that the marginal citizen is located at the right end when $p_{B} \geq 3 \cdot c \cdot \Delta$. Therefore, when $p_{B}>3 \cdot c \cdot \Delta$, official $A$ demanding the bribe $p_{A}=\frac{1}{2} \cdot c \cdot \Delta+\frac{1}{2} \cdot p_{B}$ cannot be optimal. Official $A$ can simply increase his bribe without fearing the loss of any customers. Assuming that $x=1$, we can thus derive from [3] that official $A$ 's optimal response when $p_{B}>3 \cdot c \cdot \Delta$ is $p_{A}=-c \cdot \Delta+p_{B}$.

The strategic considerations of official $B$ are the equivalent of those of official $A$; therefore, from the previous analysis, we can derive the optimal response of each official from the price demanded by his opponent.

$$
\begin{gathered}
p_{A}=\left\{\begin{array}{ccc}
\frac{1}{2} \cdot c \cdot \Delta+\frac{1}{2} \cdot p_{B} & : & 0<p_{B}<3 \cdot c \cdot \Delta \\
-c \cdot \Delta+p_{B} & : & 3 \cdot c \cdot \Delta<p_{B},
\end{array}\right. \\
p_{B}=\left\{\begin{array}{ccc}
\frac{1}{2} \cdot c \cdot \Delta+\frac{1}{2} p_{A} & : & 0<p_{A}<3 \cdot c \cdot \Delta \\
-c \cdot \Delta+p_{A} & : & 3 \cdot c \cdot \Delta<p_{A},
\end{array}\right.
\end{gathered}
$$

Making use of these reaction functions, we can derive the Nash equilibrium bribe.

$$
\tilde{p}_{A}^{*}=\tilde{p}_{B}^{*}=c \cdot \Delta
$$

The following Lemma summarizes the main result of the analysis of the bribe competition between corrupt officials that offer differentiated bureaucratic services.

Lemma 1. Competition between corrupt officials does not lead to a race to the bottom when bureaucratic services are differentiated. Bribes increase with the differences in the characteristics of the bureaucratic services $(\Delta)$.

Proof. From [8], we can derive that $\tilde{p}_{i}^{*} \geq 0$ for $c \cdot \Delta \geq 0$ and that $\frac{d \tilde{p}_{i}^{*}}{d \Delta}>0$.

\section{Stage 1: A benevolent government}

Now let us turn to the first stage of the game, the government's decision regarding the differentiation of bureaucratic services. A benevolent government may want to decrease two types of costs. Both only exist because citizens have to use the bureaucratic service of one of the two officials. First, a government may be interested in decreasing the sum of bribe payments. Second, a government may be interested in decreasing citizens' compliance costs. ${ }^{11}$ For a better understanding of a benevolent government's decision, briefly considering a case in which a government only is interested in decreasing one of the two costs is useful.

\footnotetext{
${ }^{11}$ Governments may also be interested in the equal distribution of compliance and extortion costs, as increasing evidence shows that inequality harms growth (see, for example, Lessmann (2015)). At first glance, accounting for this effect in the
} 
The sum of all bribe payments $(B C)$ is the sum of all bribes paid to both officials.

$$
B P=p_{A}^{*} x\left(p_{A}^{*}, p_{B}^{*}\right)+p_{B}^{*}\left[1-x\left(p_{A}^{*}, p_{B}^{*}\right)\right]
$$

Making use of [8] we can simplify the sum of all bribe payments to $B P=\Delta \cdot c$. From [9] and Lemma 1 , we can derive Lemma 2.

Lemma 2. In the presence of corruption, a government that is only interested in decreasing bribe payments will not aim to differentiate bureaucratic services. If possible, such a government will decrease the difference in the characteristics of the bureaucratic services to zero $\left(\Delta=0\right.$ and $\left.\mathrm{z}_{\mathrm{i}}=\frac{1}{2}\right)$.

Proof. From [8] and [9], we derive that $\frac{d B P}{d \Delta}=c$.

From Lemma 2, we know that if the only goal is to reduce bribe payments, bureaucratic services will not be differentiated. Hence, officials will be located in one place in town, will have the same hours of operation and will not differ in any other respects that are relevant to citizens. A government will thus maximize market forces, and competition will drive bribe payments to zero.

Compliance costs $(C C)$ are the sum of all the costs that citizens face because they have to use one of the officials.

$$
C C=c \cdot\left[\int_{0}^{\mathrm{z}_{\mathrm{A}}}\left[\mathrm{z}_{\mathrm{A}}-y\right]^{2} d y+\int_{\mathrm{z}_{\mathrm{A}}}^{x\left(p_{A}^{*}, p_{B}^{*}\right)}\left[y-\mathrm{z}_{\mathrm{A}}\right]^{2} d y+\int_{x\left(p_{A}^{*}, p_{B}^{*}\right)}^{\mathrm{z}_{\mathrm{B}}}\left[\mathrm{z}_{\mathrm{B}}-y\right]^{2} d y+\int_{\mathrm{z}_{\mathrm{B}}}^{1}\left[y-\mathrm{z}_{\mathrm{B}}\right]^{2} d y\right]
$$

Making use of [2] and [8], we can simplify [10] as follows:

$$
C C=\left[\Delta^{3}-[-1+\Delta]^{3}\right] \cdot \frac{\mathrm{c}}{12}
$$

From [11], we can derive Lemma 3.

Lemma 3. In the presence of corruption, a government that is only interested in decreasing compliance costs will aim to differentiate bureaucratic services. If possible, such a government will implement bureaucratic services with characteristics that are equally far from the middle and the edges of the service characteristic $\operatorname{space}\left(\Delta=\frac{1}{2} ; \mathrm{z}_{\mathrm{A}}=\frac{1}{4}\right.$ and $\left.\mathrm{z}_{\mathrm{B}}=\frac{3}{4}\right)$.

Proof. From [11], we can derive $\frac{d C C}{d \Delta}=\left[\Delta^{2}-[-1+\Delta]^{2}\right] \cdot \frac{\mathrm{c}}{4}$. From $\frac{d C C}{d \Delta}=0$, we can derive that $\Delta=\frac{1}{2}$ minimizes compliance costs. From the symmetry assumption, we can further derive that, for $\Delta=\frac{1}{2}$, the characteristics of the bureaucratic services offered by both officials have to be $\mathrm{z}_{\mathrm{A}}=\frac{1}{4}$ and $\mathrm{z}_{\mathrm{B}}=\frac{3}{4}$.

Lemma 3 tells us that, from a compliance cost perspective, the differentiation of bureaucratic services is preferable. Differentiating bureaucratic services decreases the sum of citizens' disutility when they comply with

welfare analysis seems an important task when the locations of the officials' offices are nonsymmetrical. However, I leave this question open for future research to keep the present analysis focused. 
government regulations. Citizens' disutility increases quadratically in the difference between the preferred characteristic and the actual characteristic of the bureaucratic services used. Therefore, a government can decrease compliance costs by moving the characteristic of the official on the left to the left, as long as more citizens to the left than to the right use his service. Hence, when decreasing compliance costs is a government's sole aim, it will always differentiate bureaucratic services. Lemma 2 and 3 already tell us that a benevolent government that aims to decrease compliance costs and bribe payments will face a tradeoff.

A benevolent government aims to decrease the welfare costs resulting from government regulations. Defining welfare costs in the presence of corruption is a difficult task. A common assumption in the literature is that bribe payments are merely transfers from citizens to corrupt officials and are thus welfare neutral. Often this assumption helps focus an analysis in which corruption creates direct welfare effects. A famous example is the discussion on the corruption-induced distortion of market entry (Shleifer and Vishny, 1993). However, several arguments claim that bribes also create indirect welfare losses. For instance, one argument claims that bribe income cannot be spent as simply as regular income because bribe income is illegal. Hence, bribery can create an indirect welfare effect because officials may distort their consumption. Furthermore, the distribution of income is a potential societal concern; therefore, the redistribution that results from bribery creates indirect welfare losses. For these reasons, in what follows, I will assume that a benevolent government aims to decrease compliance costs and bribe payments. ${ }^{12}$ The weight $\alpha$ tell us how much a benevolent government is concerned about bribery, i.e., how high the welfare costs are for one dollar of the bribe paid. We will refer to $\alpha$ as the social costs of bribe payments. The total welfare loss created through government regulation is as follows:

$$
W C=C C+\alpha \cdot B P
$$

Making use of [8], [9] and [10], we can simplify [12] as follows:

$$
W C=\frac{c}{12} \cdot\left[12 \cdot \alpha \cdot \Delta+1-3 \cdot \Delta+3 \cdot \Delta^{2}\right]
$$

From [13], we can derive the following proposition:

Proposition 1. In the presence of corruption, a benevolent government will only differentiate bureaucratic services when the social costs of bribe payments are low $(\alpha<1 / 4)$. In such cases, the differentiation of bureaucratic services increases as the social costs of bribe payments decrease.

Proof. From [13], we can derive $\frac{d W C}{d \Delta}=[12 \cdot \alpha-3+6 \cdot \Delta] \cdot \frac{c}{12}$. From $\frac{d W C}{d \Delta}=0$, we can derive that $\Delta=\frac{1}{2}-2 \cdot \alpha$ minimizes welfare costs as long as $\alpha<1 / 4$. When the costs of bribe payments are high, such that $\alpha>1 / 4$, then no differentiation $(\Delta=0)$ minimizes welfare costs.

From Proposition 1, we know that when the social costs of bribe payments are low, differentiated bureaucratic services may exist, even in the presence of corruption. This differentiation may occur when the redistribution of

\footnotetext{
${ }^{12}$ This does not necessarily mean that corruption has no direct welfare effects in the presence of imperfect competition among corrupt officials. When officials are not symmetrically located around the center of the service characteristic space, bribery may create a distortion of citizens' decisions to use official A or official B. In such cases, corruption influences compliance costs and can thus have a direct effect on welfare. For more details, see Appendix C.
} 
income via extortion is not societally important or when bribe income does not distort consumption. However, the higher the social costs of bribe payments are, the less a benevolent government will tend to differentiate bureaucratic services. To clarify this tendency, let us consider a simple case where $\alpha=1$. When one dollar of the bribe paid results in one dollar of welfare cost, then a benevolent government will never differentiate bureaucratic services because moving officials away from one another at $\mathrm{z}_{\mathrm{A}}=\mathrm{z}_{B}=\frac{1}{2}$ induces a bribe increase for all citizens of c. However, the decrease in total compliance costs is always smaller because compliance costs only decrease by c for the citizen at the left fringe of the service characteristic space. All the citizens to his right will face a decrease in compliance costs that is smaller than the increase in bribe payments. ${ }^{13}$ Therefore, differentiating bureaucratic services when $(\alpha=1)$ is never optimal because the decrease in compliance costs cannot compensate for the costs of the increasing extortion, which is the case as long as $\alpha>1 / 4$.

\section{BUREAUCRATIC SERVICE DIFFERENTIATION AND ANTI- CORRUPTION CAPACITIES}

So far, we have assumed that corruption is only limited by bureaucratic competition, which is not necessarily true when citizens can fight corruption by reporting extortion to the legal authorities. Let us assume that when citizens encounter a corrupt official, they can decide whether to accept the bribe or to report the extortion to the legal authorities. When a citizen reports extortion, the bureaucratic service is free of charge. However, reporting extortion is costly for citizens. The costs of reporting extortion to the legal authorities are $\bar{p}{ }^{14}$ Therefore, citizens will only report extortion if the bribe demanded by corrupt official exceeds $\bar{p}$. We will refer to $\bar{p}$ as the costs of reporting extortion. An official is penalized when a citizen appeals to the legal system and loses his entire bribe income. Therefore, a corrupt official will never demand a bribe that induces a citizen to appeal to the legal system. Hence, in terms of the literature on industrial organization, $\bar{p}$ represents a price floor. ${ }^{15}$ Considering this additional constraint, the optimal response of thee officials to the price demanded by their opponents is as follows:

$$
\begin{aligned}
& R_{A}\left(p_{B}\right)=\left\{\begin{array}{ccc}
\min \left\{\frac{1}{2} \cdot c \cdot \Delta+\frac{1}{2} \cdot p_{B}, \bar{p}\right\} & : & 0<p_{B}<3 \cdot c \cdot \Delta, \\
\min \left\{-c \cdot \Delta+p_{B}, \bar{p}\right\} & : & 3 \cdot c \cdot \Delta<p_{B},
\end{array}\right. \\
& R_{B}\left(p_{A}\right)=\left\{\begin{array}{ccc}
\min \left\{\frac{1}{2} \cdot c \cdot \Delta+\frac{1}{2} \cdot p_{A}, \bar{p}\right\} & : & 0<p_{A}<3 \cdot c \cdot \Delta, \\
\min \left\{-c \cdot \Delta+p_{A}, \bar{p}\right\} & : & 3 \cdot c \cdot \Delta<p_{A} .
\end{array}\right.
\end{aligned}
$$

Making use of these reaction functions, we can derive the new Nash equilibrium bribe as follows:

\footnotetext{
${ }^{13}$ For $\mathrm{z}_{\mathrm{A}}=\mathrm{z}_{B}=\frac{1}{2}$, the change in compliance costs of a citizen to the right of the left fringe of the service characteristic space and to the left of the marginal citizen $\left(z_{i} \in[0,1 / 2]\right)$ is $2 \cdot c \cdot\left[z_{A}-z_{i}\right]$ which is always smaller than or equal to $c$.

${ }^{14}$ To keep the analysis focused, I consider the costs of reporting extortion homogenous. However, it is possible that the bureaucratic service of processing complaints has characteristics that are also heterogeneously preferred by citizens. If so, $\bar{p}$ reflects the lowest costs of reporting extortion a citizen can have. A corrupt official will never demand a bribe higher then $\bar{p}$, assuming that he at least loses his entire bribe income because of one complaint. For example, when the service of processing complaints has the characteristic $z_{f} \in[0,1]$ and reporting extortion induces general costs of cost $r$, then $\bar{p}<$ $\min _{z_{i}} c \cdot\left[z_{f}-z_{i}\right]^{2}+r=r$.

${ }^{15}$ For a detailed analysis of the effect of price floors in normal markets with product differentiation by producers, see Kemnitz and Hemmasi (2003).
} 


$$
\left(p_{A}^{*}, p_{B}^{*}\right)=\left\{\begin{array}{ccc}
\left(\tilde{p}_{A}^{*}, \tilde{p}_{B}^{*}\right) & : \quad c \cdot \Delta<\bar{p} \\
(\bar{p}, \bar{p}) & : \quad \bar{p}<c \cdot \Delta
\end{array}\right.
$$

where $\tilde{p}_{A}^{*}=\tilde{p}_{B}^{*}=c \cdot \Delta$. From [16], we can supplement Lemma 1.

Lemma 4. In the presence of corruption, bribes are limited by either the competition between the officials or the possibility of citizens to report extortion. When the costs of reporting extortion are...

a) small $(\bar{p}<c \cdot \Delta)$, the difference between the characteristics of the bureaucratic service $(\Delta)$ has no effect on the level of bribery, which decreases with the costs of reporting extortion $(\bar{p})$;

b) high $(\bar{p}>c \cdot \Delta)$, the costs of reporting extortion $(\bar{p})$ have no effect on the level of bribery, which decreases with the difference between the characteristics of the bureaucratic services $(\Delta){ }^{16}$

Proof. The first part follows immediately from [16]. From [16], we can further derive the following:

$$
\frac{d p_{i}^{*}}{d \Delta}=\left\{\begin{array}{lll}
c & : & c \cdot \Delta<\bar{p} \\
0 & : & \bar{p}<c \cdot \Delta
\end{array} ; \frac{d p_{i}^{*}}{d \bar{p}}=\left\{\begin{array}{llc}
0 & : & c \cdot \Delta<\bar{p} \\
1 & : & \bar{p}<c \cdot \Delta
\end{array}\right.\right.
$$

Let us now return to the last stage of the game, a benevolent government's decision about whether to differentiate bureaucratic services. Without losing generality, let us assume for the sake of simplicity that $\alpha=1$; hence, the social costs of bribe payments are equal to the compliance costs. As discussed at the end of the previous section, in such cases, a benevolent government will never differentiate bureaucratic services because $\Delta=0$ minimizes the welfare loss. This differentiation decision may change when something besides competition between officials limits bribe payments. Welfare costs, which are induced by the government regulation that forces citizens to use the service of one of the two officials, can be written using [12] and [16] as follows:

$$
W C=\left\{\begin{array}{ccc}
{\left[\Delta-\frac{1}{12} \cdot[-1+\Delta]^{3}+\frac{1}{12} \cdot \Delta^{3}\right] \cdot c} & : & c \cdot \Delta<\bar{p} \\
{\left[\Delta^{3}-[-1+\Delta]^{3}\right] \cdot \frac{\mathrm{c}}{12}+\bar{p}} & : & \bar{p}<c \cdot \Delta .
\end{array}\right.
$$

From [17], we see that the tradeoff defined in Lemma 2 and Lemma 3 between compliance costs and bribe payments may not exist. If the costs of reporting extortion are low and bureaucratic services differ considerably, such that $\bar{p}<c \cdot \Delta$, then extortion is limited only by citizens' ability to complain about extortion. In this case, a further increase in the differentiation of bureaucratic services does not change the sum of the bribe payments, which is constant at $B P=\bar{p}$. Therefore, differentiating bureaucratic services may be is optimal, even when $\alpha=$ 1 , because increases in bribery costs induced by the differentiation of bureaucratic services are limited at a certain point by citizens' ability to report extortion. Therefore, we can offer the following proposition.

Proposition 2. In the presence of corruption, a benevolent government will differentiate bureaucratic services, even when the social costs of bribe payments are high $(\alpha=1)$, if anti-corruption capacities are high and thus the costs of reporting extortion are low, such that $\frac{1}{16} \cdot c>\bar{p}$.

\footnotetext{
${ }^{16}$ Lemma 4 is not necessarily true when asymmetric characteristics of bureaucratic services exist; see Appendix B for a discussion on this point.
} 
Proof. Proposition 2 follows from [17], Proposition 1 and Lemma 3. From [17], we know that two possible solutions to a benevolent government's minimization problem exist. The first solution follows from [17] and Proposition 1 and is not to differentiate. This solution is always possible because $c \cdot 0<\bar{p}$ and results in a welfare loss of $\left.W C\right|_{\Delta=0}=\frac{\mathrm{c}}{12}$. The second solution follows from [17] and Lemma 3 and involves differentiating characteristics, such that they are equally far from the middle and the edges of the service characteristic space $\left(\Delta=\frac{1}{2} ; \mathrm{z}_{\mathrm{A}}=\frac{1}{4}\right.$ and $\left.\mathrm{z}_{\mathrm{B}}=\frac{3}{4}\right)$. However, this solution is only possible when $c \cdot \frac{1}{2}<\bar{p}$ and only then crates welfare losses of $\left.W C\right|_{\Delta=1 / 2}=\frac{c}{48}+\bar{p}$. Comparing the two possible solutions, we see that $\left.W C\right|_{\Delta=0}>\left.W C\right|_{\Delta=1 / 2}$ for $\frac{1}{16} \cdot c>\bar{p}$. Hence, when $\frac{1}{16} \cdot c>\bar{p}$, differentiating $\left(\Delta=\frac{1}{2} ; \mathrm{z}_{\mathrm{A}}=\frac{1}{4}\right.$ and $\mathrm{z}_{\mathrm{B}}=$ $\left.\frac{3}{4}\right)$ is a possible and optimal solution to a benevolent government’s minimization problem.

Proposition 2 tells us that, depending on the cost of reporting extortion, a government may want to differentiate bureaucratic services. Hence, in a country with a high-quality legal system and high anti-corruption capacities in which reporting extortion is easy, a benevolent government will differentiate bureaucratic services. They differentiate because the increase in bribe payments induced by the differentiation of bureaucratic services is limited by the ability of citizens to report extortion. A new and growing literature debates the development of state capacities over time; this debate indicates that state capacities are not fixed in the long run. Hence, what happens to bureaucratic services over time when anti-corruption capacities improve is a fair question. Proposition 2 indicates that, with increasing anti-corruption capacities, bureaucratic services will tend to be differentiated. From Proposition 2 and [9], we can therefore derive the following:

Proposition 3. An exogenous increase in anti-corruption capacities that decreases the cost of reporting extortion may increase bribe payments and improve welfare.

Proof. From Proposition 2, we know that a decrease in the cost of reporting extortion $\bar{p}$ may induce a benevolent government to differentiate bureaucratic services, which increases welfare. From [9], we know that differentiation will increase bribe payments.

Improving anti-corruption capacities is a goal of many development projects around the world. Proposition 3 indicates that an overly narrow evaluation of such projects may be misleading. It is possible that such projects increase bribery and nevertheless lead to a welfare improvement. The evaluation of such development projects should consider the effect of bribery and citizens' compliance costs. The effect of the project may be that bribes have increased slightly, but the improvement of the legal system has provided the government with an opportunity to differentiate bureaucratic services and thereby decrease the compliance costs substantially.

\section{CONCLUSION}

This paper discusses when and under what circumstances the differentiation bureaucratic services will occur in the presence of corruption. A model of imperfect competition among corrupt officials was thus developed, which, to the best of my knowledge, is new to the literature. The analysis has revealed that a benevolent government faces a tradeoff between bribery and compliance costs in the presence of corruption. The 
differentiation of bureaucratic services decreases compliance costs but increases bribe payments. This paper focuses on analyzing this tradeoff.

From the analysis, several testable hypotheses emerge. The model predicts that the differentiation of bureaucratic services will not occur in countries where the social costs of bribe payments are high. The differentiation of bureaucratic services will not occur in countries with low anti-corruption capacities that result in high costs of reporting extortion. Furthermore, increasing anti-corruption capacities may increase bribery.

The analysis also helps guide the evaluation of development projects. The analysis indicates that an overly narrow evaluation of development projects that aim to improve welfare by improving anti-corruption capacities may be misleading. An improvement in anti-corruption capacities that decreases the cost of reporting extortion may not only increase bribery but also improve welfare because compliance costs decrease. To evaluate the success of a project that improves anti-corruption capacities, examining its effects on bribery and compliance costs is thus necessary.

\section{REFERENCES}

Arikan, G.G., 2004. Fiscal decentralization: A remedy for corruption? Int. Tax Public Finan. 11, 175-195.

Choi, J., Thum, M., 2003. The dynamics of corruption with the ratchet effect. J. Public Econ. 87, 427-443.

Choi, J., Thum, M., 2004. The economics of repeated extortion. Rand. J. Econ. 35, 203-223.

Choi, J., Thum, M., 2005. Corruption and the shadow economy. Int. Econ. Rev. 46, 817-836.

d'Aspremont, C., Gabszewicz, J.J., Thisse, J.F., 1979. On Hotelling's" Stability in competition”. Econometrica. 47, 1145-1150.

Diabya, A., Sylwester, K., 2014. Bureaucratic competition and public corruption: Evidence from transition countries. Eur. J. Polit. Econ. 35, 75-87.

Drugov, M., 2010. Competition in bureaucracy and corruption. J. Dev. Econ. 92, 107-114.

Fisman, R., Gatti, R., 2002a. Decentralization and corruption: Evidence across countries. J. Public Econ. 83, 325-345.

Fisman, R., Gatti, R., 2002b. Decentralization and corruption: Evidence from US federal transfer programs. Public Choice. 131, 25-35.

Hotelling, H., 1929. Stability in competition. The Economic Journal. 39, 41-57.

Kemnitz, A., Hemmasi., C., 2003. Price ceilings and quality competition. Economics Bulletin. 4, 1-9.

Lessmann, C., 2015. Regional inequality and internal conflict. German Economic Review. In press.

Lessmann, C., Markwardt, G., 2010. One size fits all? Decentralization, corruption, and the monitoring of bureaucrats. World Development. 38, 631-646. 
Oates, W.E., 1972. Fiscal federalism. Harcourt Brace Jovanovich, New York.

Olken, B.A., Barron, P., 2009. The simple economics of extortion: Evidence from trucking in Aceh. J. Polit. Econ. 117, 417-252.

Khan, A.Q., Khwaja, A.I., Olken, B.A., 2015. Tax farming redux: Experimental evidence on performance pay for tax collectors. Q. J. Econ. In press.

Rose-Ackerman, S., 1978. Corruption: A study in Political Economy. Academic, New York.

Ryvkin, D., Serra, D., 2013. Does competition among public offices reduce corruption? An experiment. Social Science Research Network. http://dx.doi.org/10.2139/ssrn.2383879.

Seidel, A., Thum, M. 2016. Tax Evasion, Corruption and Market Entry. Scottish J. Polit. Econ., In press, DOI: 10.1111/sjpe.12100.

Shleifer, A., Vishny, R., 1993. Corruption. Q. J. Econ. 108, 599-617.

Svensson, J., 2003. Who must pay bribes and how much? Evidence from a cross section of firms. Q. J. Econ. 118, 207-230.

Transparency International., 2011. Daily Lives and Corruption, Public Opinion in Southern Africa. Transparency International, Berlin.

World Bank., 2016. Doing Business 2016: Measuring Regulatory Quality and Efficiency. World Bank Group, Washington, DC. DOI: 10.1596/978-1-4648-0667-4.

\section{APPENDIX}

\section{APPENDIX A (ASYMMETRIC CHARACTERISTICS)}

In what follows, I sketch the main analysis of the paper without assuming that the characteristics of the bureaucratic services have to be symmetric. The service deliveries of the two corrupt officials differ with respect to a one-dimensional characteristic. The amount of characteristics is measured by $z_{i}$, where $z_{i} \in[0,1]$. Without losing generality, let us assume that $z_{A}<z_{B}$. Hence, official $A$ always offers a service to the left of the service of official $B$ in the service characteristic space. With asymmetric characteristics, the reaction functions of the officials are as follows:

$$
\begin{gathered}
R_{A}\left(p_{B}\right)=\left\{\begin{array}{ccc}
\frac{1}{2} \cdot\left[\left[\mathrm{z}_{\mathrm{B}}^{2}-\mathrm{z}_{\mathrm{A}}^{2}\right] \cdot \mathrm{c}+p_{B}\right] & : & 0<p_{B}<\left[\mathrm{z}_{\mathrm{B}}-\mathrm{z}_{\mathrm{A}}\right] \cdot\left[4-\mathrm{z}_{\mathrm{A}}-\mathrm{z}_{\mathrm{B}}\right] \cdot \mathrm{c} \\
{\left[2 \cdot \mathrm{z}_{\mathrm{A}}-2 \cdot \mathrm{z}_{\mathrm{B}}+\mathrm{z}_{\mathrm{B}}^{2}-\mathrm{z}_{\mathrm{A}}^{2}\right] \cdot \mathrm{c}+p_{B}} & : & {\left[\mathrm{z}_{\mathrm{B}}-\mathrm{z}_{\mathrm{A}}\right] \cdot\left[4-\mathrm{z}_{\mathrm{A}}-\mathrm{z}_{\mathrm{B}}\right] \cdot \mathrm{c}<p_{B},}
\end{array}\right. \\
R_{B}\left(p_{A}\right)=\left\{\begin{array}{ccc}
\frac{1}{2} \cdot\left[\left[2 \cdot \mathrm{z}_{\mathrm{B}}-2 \cdot \mathrm{z}_{\mathrm{A}}-\mathrm{z}_{\mathrm{B}}^{2}+\mathrm{z}_{\mathrm{A}}^{2}\right] \cdot \mathrm{c}+\mathrm{p}_{\mathrm{A}}\right] & : & 0<p_{A}<\left[\mathrm{z}_{\mathrm{B}}-\mathrm{z}_{\mathrm{A}}\right] \cdot\left[2+\mathrm{z}_{\mathrm{A}}+\mathrm{z}_{\mathrm{B}}\right] \cdot \mathrm{c} \\
{\left[\mathrm{z}_{\mathrm{A}}^{2}-\mathrm{z}_{\mathrm{B}}^{2}\right] \cdot \mathrm{c}+p_{A}} & : & {\left[\mathrm{z}_{\mathrm{B}}-\mathrm{z}_{\mathrm{A}}\right] \cdot\left[2+\mathrm{z}_{\mathrm{A}}+\mathrm{z}_{\mathrm{B}}\right] \cdot \mathrm{c}<p_{A},}
\end{array}\right.
\end{gathered}
$$


The resulting Nash equilibrium prices are as follows:

$$
\tilde{p}_{A}^{*} \equiv \frac{1}{3} \cdot\left[\mathrm{z}_{\mathrm{B}}-\mathrm{z}_{\mathrm{A}}\right] \cdot\left[2+\mathrm{z}_{\mathrm{A}}+\mathrm{z}_{\mathrm{B}}\right] \cdot \mathrm{c} \text { and } \tilde{p}_{B}^{*} \equiv \frac{1}{3} \cdot\left[\mathrm{z}_{\mathrm{B}}-\mathrm{z}_{\mathrm{A}}\right] \cdot\left[4-\mathrm{z}_{\mathrm{A}}-\mathrm{z}_{\mathrm{B}}\right] \cdot \mathrm{c}
$$

The total welfare loss created induced by the government regulation is as follows:

$$
W C=C C+\alpha \cdot B P
$$

Making use of [9], [10] and [20], [21] can be written as follows:

$$
\begin{gathered}
W C=-\left[\left[-\alpha+\frac{5}{4}\right] \cdot \mathrm{z}_{\mathrm{B}}^{3}+\left[\left[-\alpha+\frac{5}{4}\right] \cdot \mathrm{z}_{\mathrm{A}}+2 \cdot \alpha-7\right] \cdot \mathrm{z}_{\mathrm{B}}^{2}+\left[\left[-\frac{5}{4}+\alpha\right] \cdot \mathrm{z}_{\mathrm{A}}^{2}-10 \cdot \alpha+8\right] \cdot \mathrm{z}_{\mathrm{B}}\right. \\
\left.-3+\left[-\frac{5}{4}+\alpha\right] \cdot \mathrm{z}_{\mathrm{A}}^{3}-2 \cdot[\alpha+1] \cdot \mathrm{z}_{\mathrm{A}}^{2}+[10 \cdot \alpha+1] \cdot \mathrm{z}_{\mathrm{A}}\right] \cdot \frac{c}{9}
\end{gathered}
$$

The government maximization problem is as follows:

Maximize: $W=-W C\left(\mathrm{z}_{\mathrm{A}}, \mathrm{z}_{\mathrm{B}}\right)$

Subject to: $\mathrm{z}_{\mathrm{B}}-\mathrm{z}_{\mathrm{A}} \geq 0$ and $1-\mathrm{z}_{\mathrm{B}} \geq 0$ and the non-negativity constraint $\mathrm{z}_{\mathrm{B}} \geq 0$ and $\mathrm{z}_{\mathrm{A}} \geq 0$.

The Lagrangian for the problem is as follows:

$$
Z=-W C+\lambda_{1} \cdot\left[\mathrm{z}_{\mathrm{B}}-\mathrm{z}_{\mathrm{A}}\right]+\lambda_{2} \cdot\left[1-\mathrm{z}_{\mathrm{B}}\right]
$$

where $\lambda_{1}$ and $\lambda_{2}$ are the Lagrange multipliers. The Kuhn-Tucker conditions for the government's maximization problem are as follows:

$$
\begin{aligned}
& \mathrm{z}_{\mathrm{A}} \cdot \frac{d Z}{d \mathrm{z}_{\mathrm{A}}}=\mathrm{z}_{\mathrm{A}} \cdot\left[\left[[12 \cdot \alpha-15] \cdot \mathrm{z}_{\mathrm{A}}^{2}+\left[\left[8 \cdot \mathrm{z}_{\mathrm{B}}-16\right] \cdot \alpha-10 \cdot \mathrm{z}_{\mathrm{B}}-16\right] \cdot \mathrm{z}_{\mathrm{A}}-4 \cdot \mathrm{z}_{\mathrm{B}}^{2} \cdot \alpha+4\right.\right. \\
& \left.\left.+40 \cdot \alpha+5 \cdot \mathrm{z}_{\mathrm{B}}^{2}\right] \cdot \frac{\mathrm{c}}{36}-\lambda_{1}\right]=0 \\
& \mathrm{z}_{\mathrm{B}} \cdot \frac{d Z}{d \mathrm{z}_{\mathrm{B}}}=\mathrm{z}_{\mathrm{B}} \cdot\left[\left[[15-12 \cdot \alpha] \cdot \mathrm{z}_{\mathrm{B}}^{2}+\left[\left[16-8 \cdot \mathrm{z}_{\mathrm{A}}\right] \cdot \alpha-56+10 \cdot \mathrm{z}_{\mathrm{A}}\right] \cdot \mathrm{z}_{\mathrm{B}}+4 \cdot \mathrm{z}_{\mathrm{A}}{ }^{2} \cdot \alpha-5\right.\right. \\
& \left.\left.\cdot \mathrm{z}_{\mathrm{A}}^{2}-40 \cdot \alpha+32\right] \cdot \frac{\mathrm{c}}{36}+\lambda_{1}-\lambda_{2}\right]=0 \\
& \lambda_{1} \cdot \frac{d Z}{d \lambda_{1}}=\lambda_{1} \cdot\left[\mathrm{z}_{\mathrm{B}}-\mathrm{z}_{\mathrm{A}}\right]=0 \\
& \lambda_{2} \cdot \frac{d Z}{d \lambda_{2}}=\lambda_{2} \cdot\left[1-\mathrm{z}_{\mathrm{B}}\right]=0 \\
& \frac{d Z}{d \mathrm{z}_{\mathrm{A}}}=\left[[12 \cdot \alpha-15] \cdot \mathrm{z}_{\mathrm{A}}^{2}+\left[\left[8 \cdot \mathrm{z}_{\mathrm{B}}-16\right] \cdot \alpha-10 \cdot \mathrm{z}_{\mathrm{B}}-16\right] \cdot \mathrm{z}_{\mathrm{A}}-4 \cdot \mathrm{z}_{\mathrm{B}}{ }^{2} \cdot \alpha+4+40 \cdot \alpha+5\right. \\
& \left.\cdot \mathrm{z}_{\mathrm{B}}^{2}\right] \cdot \frac{\mathrm{c}}{36}-\lambda_{1} \leq 0 \\
& \frac{d Z}{d \mathrm{z}_{\mathrm{B}}}=\left[[15-12 \cdot \alpha] \cdot \mathrm{z}_{\mathrm{B}}^{2}+\left[\left[16-8 \cdot \mathrm{z}_{\mathrm{A}}\right] \cdot \alpha-56+10 \cdot \mathrm{z}_{\mathrm{A}}\right] \cdot \mathrm{z}_{\mathrm{B}}+4 \cdot \mathrm{z}_{\mathrm{A}}^{2} \cdot \alpha-5 \cdot \mathrm{z}_{\mathrm{A}}^{2}-40 \cdot \alpha\right. \\
& +32] \cdot \frac{c}{36}+\lambda_{1}-\lambda_{2} \leq 0 \\
& \frac{d Z}{d \lambda_{1}}=\mathrm{z}_{\mathrm{B}}-\mathrm{z}_{\mathrm{A}} \geq 0
\end{aligned}
$$




$$
\begin{gathered}
\frac{d Z}{d \lambda_{2}}=1-\mathrm{z}_{\mathrm{B}} \geq 0 \\
\mathrm{z}_{\mathrm{A}}, \mathrm{z}_{\mathrm{B}} \lambda_{1}, \lambda_{2} \geq 0
\end{gathered}
$$

To find the solution to the maximization problem, let us systematically assume that the different constraints bind. Therefore, we have to evaluate four cases. I will always first derive the points $S=\left(\mathrm{z}_{\mathrm{A}}, \mathrm{z}_{\mathrm{B}} \lambda_{1}, \lambda_{2}\right)$ that fulfill the equality constraints of the KKT conditions, which result from the cases assumptions. Then, I will test whether the inequality KKT conditions are satisfied for $\boldsymbol{S}$.

Assume that $\lambda_{2}=\mathbf{0}$ and $\lambda_{1}>\mathbf{0}$. Solving [24], [25] and [26] for $\mathrm{z}_{\mathrm{A}}, \mathrm{z}_{\mathrm{B}}$ and $\lambda_{1}$ then yields the following points:

$$
\boldsymbol{S}_{1}=\left(0,0, \lambda_{1}, 0\right) \text { and } \boldsymbol{S}_{2}=\left(\frac{1}{2}, \frac{1}{2}, \alpha \cdot c-\frac{c}{4}, 0\right)
$$

Substituting $\boldsymbol{S}_{\mathbf{1}}$ in [28] and [29] reveals that no $\lambda_{1} \geq 0$ exists to satisfy these KKT conditions. Hence, $\boldsymbol{S}_{\mathbf{1}}$ is not a solution to the maximization problem. For $\boldsymbol{S}_{2}$, all KKT conditions are always fulfilled, except $\lambda_{1} \geq 0$, which is only true, when $\frac{1}{4}<\alpha$. Hence, $S_{2}$ is a candidate point to the maximization problem when $\frac{1}{4}<\alpha$.

Assume $\lambda_{2}>\mathbf{0}$ and $\lambda_{1}=\mathbf{0}$. Solving [24], [25] and [27] for $\mathrm{z}_{\mathrm{A}}, \mathrm{z}_{\mathrm{B}}$ and $\lambda_{2}$ then yields the following points:

$$
\begin{gathered}
\boldsymbol{S}_{3}=\left(\frac{4 \cdot \alpha+13+2 \cdot \sqrt{-104 \cdot \alpha^{2}+134 \cdot \alpha+76}}{12 \cdot \alpha-15}, 1,0,-2 \cdot c \cdot[2 \cdot \alpha-7]\right. \\
\left.\cdot \frac{4 \cdot \alpha+13+2 \cdot \sqrt{-104 \cdot \alpha^{2}+134 \cdot \alpha+76}}{324 \cdot \alpha-405}-\frac{4}{3} \cdot \alpha \cdot c-\frac{1}{3} \cdot c\right), \\
\boldsymbol{S}_{4}=\left(\frac{4 \cdot \alpha+13-2 \cdot \sqrt{-104 \cdot \alpha^{2}+134 \cdot \alpha+76}}{12 \cdot \alpha-15}, 1,0,-2 \cdot c \cdot[2 \cdot \alpha-7]\right. \\
\left.\cdot \frac{4 \cdot \alpha+13-2 \cdot \sqrt{-104 \cdot \alpha^{2}+134 \cdot \alpha+76}}{324 \cdot \alpha-405}-\frac{4}{3} \cdot \alpha \cdot c-\frac{1}{3} \cdot c\right)
\end{gathered}
$$

and $\boldsymbol{S}_{\mathbf{5}}=\left(0,1,0,-\alpha \cdot c-\frac{1}{4} \cdot c\right)$.

Substituting $\boldsymbol{S}_{\mathbf{3}}$ in [30] and [29] reveals that [30] can only be true when $\alpha<5 / 4$. However, $\mathrm{z}_{\mathrm{A}}>0$ is only true when $\alpha>5 / 4$. Hence, $\boldsymbol{S}_{\mathbf{3}}$ is not a solution to the maximization problem. Substituting $\boldsymbol{S}_{\mathbf{4}}$ in [30] and [29] reveals that [30] can only be true when $\alpha<4 / 5$. However, $\lambda_{2}>0$ is only true when $4 / 5<[67+27$. $\sqrt{17}] / 104<\alpha$. Hence, $\boldsymbol{S}_{\mathbf{4}}$ is not a solution to the maximization problem. $\boldsymbol{S}_{\mathbf{5}}$ is also not a solution to the maximization problem because $\lambda_{2}=-\alpha \cdot c-1 / 4 \cdot c<0$.

Assume $\lambda_{2}>\mathbf{0}$ and $\lambda_{1}>\mathbf{0}$. Solving [24], [25], [26] and [27] for $z_{A}, z_{B}, \lambda_{1}$ and $\lambda_{2}$ then yields the following: point

$$
\boldsymbol{S}_{6}=\left(1,1, \frac{10}{9} \cdot \alpha \cdot c-\frac{8}{9} \cdot c,-c\right)
$$


$\boldsymbol{S}_{6}$ is not a solution to the maximization problem because $\lambda_{2}=-c<0$.

Assume $\lambda_{2}=\mathbf{0}$ and $\lambda_{1}=\mathbf{0}$. Solving [24] and [25] for $\mathrm{z}_{\mathrm{A}}$ and $\mathrm{z}_{\mathrm{B}}$ then yields the following points:

$$
\begin{gathered}
\boldsymbol{S}_{\mathbf{7}}=\left(\frac{4 \cdot \alpha+4+3 \cdot \sqrt{-16 \cdot \alpha^{2}+24 \cdot \alpha+13}, \frac{1}{8}}{8 \cdot \alpha-10}, \frac{[4 \cdot \alpha+4] \cdot \sqrt{-16 \cdot \alpha^{2}+24 \cdot \alpha+13}-48 \cdot \alpha^{2}+96 \cdot \alpha-45}{\left[6+\sqrt{-16 \cdot \alpha^{2}+24 \cdot \alpha+13}\right] \cdot\left[-\frac{5}{4}+\alpha\right]}, 0,0\right), \\
\boldsymbol{S}_{\mathbf{8}}=\left(\begin{array}{c}
\frac{4 \cdot \alpha+4-3 \cdot \sqrt{-16 \cdot \alpha^{2}+24 \cdot \alpha+13}}{8 \cdot \alpha-10}, \frac{1}{8} \\
\cdot \frac{[4 \cdot \alpha+4] \cdot \sqrt{-16 \cdot \alpha^{2}+24 \cdot \alpha+13}+48 \cdot \alpha^{2}-96 \cdot \alpha+45}{\left[-\frac{5}{4}+\alpha\right] \cdot\left[-6+\sqrt{-16 \cdot \alpha^{2}+24 \cdot \alpha+13}\right]}, 0,0
\end{array}\right), \\
\boldsymbol{S}_{\mathbf{9}}=\left(\frac{8 \cdot \alpha+8+2 \cdot \sqrt{-104 \cdot \alpha^{2}+170 \cdot \alpha+31}}{12 \cdot \alpha-15}, 0,0,0\right), \\
=\left(\frac{8 \cdot \alpha+8-2 \cdot \sqrt{-104 \cdot \alpha^{2}+170 \cdot \alpha+31}}{12 \cdot \alpha-15}, 0,0,0\right)
\end{gathered}
$$

and $\boldsymbol{S}_{\mathbf{1 1}}=\left(\frac{1}{4}+\alpha,-\alpha+\frac{3}{4}, 0,0\right)$.

Substituting $\boldsymbol{S}_{\mathbf{8}}$ in [30] and [29] reveals that [30] can only be true when $\alpha<5 / 4$. However, substituting $\boldsymbol{S}_{\mathbf{8}}$ into [31] reveals that [31] can only be true when $\alpha>5 / 4$. Hence, $\boldsymbol{S}_{\mathbf{8}}$ is not a solution to the maximization problem. Substituting $\boldsymbol{S}_{\mathbf{9}}$ into [30] and [29] reveals that [30] can only be true when $\alpha<5 / 4$. However, substituting $\boldsymbol{S}_{\mathbf{9}}$ into [31] reveals that [31] can only be true when $5 / 4<\alpha<[3+\sqrt{22}] / 4$. Hence, $\boldsymbol{S}_{\mathbf{9}}$ is not a solution to the maximization problem. $\boldsymbol{S}_{\mathbf{9}}$ and $\boldsymbol{S}_{\mathbf{1 0}}$ are not solutions to the maximization problem because [30] is never true as long as $\mathrm{z}_{\mathrm{B}}=0$ and $\mathrm{z}_{\mathrm{A}}>0$. For $\boldsymbol{S}_{\mathbf{1 1}}$, all KKT conditions are always fulfilled, except $\lambda_{1} \geq 0$, which is only true when $\frac{1}{4}>\alpha$. Hence, $\boldsymbol{S}_{\mathbf{1 1}}$ is a candidate point to the maximization problem when $\frac{1}{4}>\alpha$.

The last step that we have to undertake involves testing whether $\boldsymbol{S}_{\mathbf{2}}$ and $\boldsymbol{S}_{\mathbf{1 1}}$ fulfill the sufficiency condition for a maximum. We must test them because the government may not face a concave programing problem. From [22], we can derive that the Hessian matrixes for $\boldsymbol{S}_{\mathbf{2}}$ and $\boldsymbol{S}_{\mathbf{1 1}}$ are as follows:

$$
H_{2}=\left[\begin{array}{cc}
-c & 0 \\
0 & -c
\end{array}\right], H_{11}=\frac{c}{36}\left[\begin{array}{cc}
16 \cdot \alpha^{2}-24 \cdot \alpha-31 & 16 \cdot \alpha^{2}-24 \cdot \alpha+5 \\
16 \cdot \alpha^{2}-24 \cdot \alpha+5 & 16 \cdot \alpha^{2}-24 \cdot \alpha-31
\end{array}\right]
$$

Clearly, $\operatorname{det} H_{2,1}=-c<0$ and $\operatorname{det} H_{2,2}=c^{2}>0$; hence, $\boldsymbol{S}_{\mathbf{2}}$ is a maximum. Furthermore, $\boldsymbol{S}_{\mathbf{1 1}}$ is a maximum because $\operatorname{det} H_{11,1}=\left[16 \cdot \alpha^{2}-24 \cdot \alpha-31\right] \cdot c / 36<0$ and $\operatorname{det} H_{11,2}=-\left[16 \cdot \alpha^{2}-24 \cdot \alpha-13\right] \cdot c^{2} / 18>0$ for $\alpha<\frac{1}{4}$. The solution to the maximization problem is thus the following: 


$$
\left(\mathrm{z}_{\mathrm{A}}^{*}, \mathrm{z}_{\mathrm{B}}^{*}\right)=\left\{\begin{array}{cl}
\left(\frac{1}{4}+\alpha,-\alpha+\frac{3}{4}\right) & : \quad \alpha<\frac{1}{4} \\
\left(\frac{1}{2}, \frac{1}{2}\right) & : \frac{1}{4}<\alpha,
\end{array}\right.
$$

Hence, the solution to a benevolent government's optimization problem is always symmetric.

\section{APPENDIX B (EXTORTION WITH ASYMMETRIC CHARACTERISTICS AND ANTI-CORRUPTION CAPACITIES)}

Let us now turn to the cases where citizens can report extortion and the characteristics of the bureaucratic services can be asymmetric. For simplicity and without losing generality, let us focus on cases of asymmetry where $z_{A} \leq 1-z_{B}$. Hence, official $A$ always is closer to the left fringe of the service characteristic space than official $B$ is to the right fringe of the service characteristic space. Considering these additional constraints, the optimal response of the officials to the price demanded by their opponents is as follows:

$$
\begin{aligned}
& R_{A}\left(p_{B}\right) \\
= & \left\{\begin{array}{ccc}
\min \left\{\frac{1}{2} \cdot\left[\left[\mathrm{z}_{\mathrm{B}}^{2}-\mathrm{z}_{\mathrm{A}}^{2}\right] \cdot \mathrm{c}+p_{B}\right], \bar{p}\right\} & : & 0<p_{B}<\left[\mathrm{z}_{\mathrm{B}}-\mathrm{z}_{\mathrm{A}}\right] \cdot\left[4-\mathrm{z}_{\mathrm{A}}-\mathrm{z}_{\mathrm{B}}\right] \cdot \mathrm{c} \\
\min \left\{\left[2 \cdot \mathrm{z}_{\mathrm{A}}-2 \cdot \mathrm{z}_{\mathrm{B}}+\mathrm{z}_{\mathrm{B}}^{2}-\mathrm{z}_{\mathrm{A}}^{2}\right] \cdot \mathrm{c}+p_{B}, \bar{p}\right\} & : & {\left[\mathrm{z}_{\mathrm{B}}-\mathrm{z}_{\mathrm{A}}\right] \cdot\left[4-\mathrm{z}_{\mathrm{A}}-\mathrm{z}_{\mathrm{B}}\right] \cdot \mathrm{c}<p_{B},}
\end{array}\right. \\
R_{B}\left(p_{A}\right) & \left\{\begin{array}{ccc}
\min \left\{\frac{1}{2} \cdot\left[\left[2 \cdot \mathrm{z}_{\mathrm{B}}-2 \cdot \mathrm{z}_{\mathrm{A}}-\mathrm{z}_{\mathrm{B}}^{2}+\mathrm{z}_{\mathrm{A}}^{2}\right] \cdot \mathrm{c}+\mathrm{p}_{\mathrm{A}}\right], \bar{p}\right\} & : & 0<p_{A}<\left[\mathrm{z}_{\mathrm{B}}-\mathrm{z}_{\mathrm{A}}\right] \cdot\left[2+\mathrm{z}_{\mathrm{A}}+\mathrm{z}_{\mathrm{B}}\right] \cdot \mathrm{c} \\
\min \left\{\left[\mathrm{z}_{\mathrm{A}}^{2}-\mathrm{z}_{\mathrm{B}}^{2}\right] \cdot \mathrm{c}+p_{A}, \bar{p}\right\} & : & {\left[\mathrm{z}_{\mathrm{B}}-\mathrm{z}_{\mathrm{A}}\right] \cdot\left[2+\mathrm{z}_{\mathrm{A}}+\mathrm{z}_{\mathrm{B}}\right] \cdot \mathrm{c}<p_{A},}
\end{array}\right.
\end{aligned}
$$

The resulting Nash equilibrium prices are as follows:

$$
\left(p_{A}^{*}, p_{B}^{*}\right)=\left\{\begin{array}{clr}
\left(\tilde{p}_{A}^{*}, \tilde{p}_{B}^{*}\right) & : \overline{p_{H}}<\bar{p} \\
\left(\frac{1}{2} \cdot\left[\left[\mathrm{z}_{\mathrm{B}}^{2}-\mathrm{z}_{\mathrm{A}}^{2}\right] \cdot \mathrm{c}+\bar{p}\right], \bar{p}\right) & : \overline{p_{H}}>\bar{p}>\overline{p_{L}} \\
(\bar{p}, \bar{p}) & : & \bar{p}<\overline{p_{L}}
\end{array}\right.
$$

where $\tilde{p}_{A}^{*} \equiv \frac{1}{3} \cdot\left[\mathrm{z}_{\mathrm{B}}-\mathrm{z}_{\mathrm{A}}\right] \cdot\left[2+\mathrm{z}_{\mathrm{A}}+\mathrm{z}_{\mathrm{B}}\right] \cdot \mathrm{c} ; \tilde{p}_{B}^{*} \equiv \frac{1}{3} \cdot\left[\mathrm{z}_{\mathrm{B}}-\mathrm{z}_{\mathrm{A}}\right] \cdot\left[4-\mathrm{z}_{\mathrm{A}}-\mathrm{z}_{\mathrm{B}}\right] \cdot \mathrm{c} ; \overline{p_{L}} \equiv\left[\mathrm{z}_{\mathrm{B}}^{2}-\mathrm{z}_{\mathrm{A}}^{2}\right] \cdot \mathrm{c} ; \quad$ and $\overline{p_{H}} \equiv \frac{1}{3} \cdot\left[\mathrm{z}_{\mathrm{B}}-\mathrm{z}_{\mathrm{A}}\right] \cdot\left[2+\mathrm{z}_{\mathrm{B}}-\mathrm{z}_{\mathrm{A}}\right] \cdot \mathrm{c}$.

From [37], we see that, with asymmetric characteristics, the competitive forces and the possibility of citizens reporting extortion can simultaneously limit bribe payments, for example, when $\overline{p_{H}}>\bar{p}>\overline{p_{L}}$. In such cases, the possibility of citizens reporting extortion keeps the bribe demanded by official $B$ at bay, while the bribe demanded by official $A$ is limited by the competition that official $B$ imposes. Official $A$ will demand an even smaller bribe than official $B$. Such cases only occurs when official $A$ is closer to the left edge of the service characteristic space than official $B$ and when $\bar{p}$ is medium-sized.

\section{APPENDIX C (THE DIRECT EFFECT OF CORRUPTION ON WELFARE)}


The marginal citizen will always prefer a characteristic that is in between the officials' characteristics when they are symmetric. From $z_{A}=1-z_{B}$, [1] and [37], the following can be derived:

$$
x=\frac{z_{B}-z_{A}}{2}=\frac{1}{2}
$$

As long as the marginal citizen always prefers a characteristic that is in between the officials' characteristics, all citizens may pay a bribe but can choose the official who minimizes their compliance costs. This choice may changes when the officials' characteristics are asymmetric. When the officials' characteristics are symmetric, we know from [37] that, when $\overline{p_{H}}>\bar{p}>\overline{p_{L}}$, official $A$ will demand a smaller bribe than official $B$. Assuming that $\overline{p_{H}}>\bar{p}>\overline{p_{L}}$, we can derive the following about the marginal citizen from [1].

$$
x=\frac{\left[\mathrm{z}_{\mathrm{B}}^{2}-\mathrm{z}_{\mathrm{A}}^{2}\right] \cdot \mathrm{c}+\bar{p}}{4 \cdot\left[z_{B}-z_{A}\right] \cdot \mathrm{c}}>\frac{z_{B}-z_{A}}{2}
$$

Hence, the marginal citizen is inefficiently close to official $B$. Therefore, with non-symmetric characteristics, corruption may induce direct welfare costs, as it distorts the minimization of citizens' compliance costs.

\section{APPENDIX D (BUREAUCRATIC SERVICE DIFFERENTIATION AND ANTI- CORRUPTION CAPACITIES WITH ASYMMETRIC CHARACTERISTICS)}

When characteristics are asymmetric, such that $\overline{p_{H}}>\bar{p}>\overline{p_{L}}$, then the bribe equilibrium changes. Therefore, the question is whether for a benevolent government inducing such a situation can be optimal. To ensure that this is not the case, let us assume that the government sets $z_{A}$ and $z_{B}$, such that $\overline{p_{H}}>\bar{p}>\overline{p_{L}}$; hence,

$$
\frac{1}{3} \cdot\left[\mathrm{z}_{\mathrm{B}}-\mathrm{z}_{\mathrm{A}}\right] \cdot\left[2+\mathrm{z}_{\mathrm{B}}-\mathrm{z}_{\mathrm{A}}\right] \cdot \mathrm{c}>\bar{p}>\left[\mathrm{z}_{\mathrm{B}}^{2}-\mathrm{z}_{\mathrm{A}}^{2}\right] \cdot \mathrm{c}
$$

is true. Then, making use of [9], [10], [37] and the assumption that $\alpha=1$, we can derive the following:

$$
\frac{d W C}{d \mathrm{z}_{\mathrm{A}}}=\frac{3}{16} \cdot\left[\left[\mathrm{z}_{\mathrm{A}}-\frac{1}{3} \cdot \mathrm{z}_{\mathrm{B}}\right] \cdot\left[\mathrm{z}_{\mathrm{A}}-\mathrm{z}_{\mathrm{B}}\right] \cdot c+\frac{1}{3} \cdot \bar{p}\right] \cdot \frac{\left[\mathrm{z}_{\mathrm{A}}^{2}-\mathrm{z}_{\mathrm{B}}^{2}\right] \cdot c-\bar{p}}{c \cdot\left[\mathrm{z}_{\mathrm{A}}-\mathrm{z}_{\mathrm{B}}\right]^{2}}<0
$$

Hence, setting $z_{A}$ and $z_{B}$, such that $\overline{p_{H}}>\bar{p}>\overline{p_{L}}$, can never be optimal because, as long as $\overline{p_{H}}>\bar{p}>\overline{p_{L}}$, increasing $z_{\mathrm{A}}$ is always the best option. Therefore, an asymmetric solution, such that $z_{A}<1-z_{B}$, is not possible. Vice versa, setting the characteristics, such that $z_{A}>1-z_{B}$, is not optimal. 